\title{
Emotion and COVID-19: Toward an Equitable Pandemic Response
}

\author{
Bennett Allen (B)
}

Received: 13 October 2020 / Accepted: 30 March 2021 / Published online: 31 August 2021

(C) Journal of Bioethical Inquiry Pty Ltd. 2021

\begin{abstract}
This article discusses the ways in which healthcare professionals can use emotion as part of developing an ethical response to the COVID-19 pandemic. Affect theory, a growing approach to inquiry in the social sciences and humanities that appraises the historical and cultural contexts of emotions as expressed through art and politics, offers a frame for clinicians and researchers to consider ethical questions that surround the reopening of the United States economy in the wake of COVID-19. This article uses affect theory to describe how healthcare workers' emotions are useful for formulating a reopening plan grounded in collective action and a duty to do no harm.
\end{abstract}

Keywords COVID-19 - Affect theory $\cdot$ Public health ethics · Epidemiology

America is back in business. This is the optimistic message of our federal and state governments. But for many individuals working in healthcare, this message is disconcerting. How many deaths are too many for an epidemiologist modelling the trajectory and impact of the pandemic? For a nurse or physician

B. Allen $(\bowtie)$

Center for Opioid Epidemiology and Policy, Department of Population Health, New York University Grossman

School of Medicine, 180 Madison Avenue, 4th Floor,

New York, NY 10016, USA

e-mail: bennett.allen@nyulangone.org providing palliative care on a COVID-19 unit? For a health aide in a nursing home sieged by the virus?

Medical and public health professionals overwhelmed by COVID-19 may find guidance and solace by supplementing the empirical with the interpretive. Specifically, affect theory-broadly, the study of how feelings and emotions shape culture and are reflected in literature, popular media, and politics (Berlant and Greenwald 2012)—offers a dynamic lens through which to make sense of our current economic, political, and epidemiologic moment. Central to affect theory is the concept that emotions have histories (Reddy 2001). Distinct from but indebted to psychology and the cognitive sciences, affect theory affirms that taking stock of the social and political contexts in which certain emotions are considered useful (e.g., righteous anger) or deemed appropriate or inappropriate can help us better understand the present (Sedgwick, 2003).

A range of feelings arise during clinical care, and an undeniable power can be derived from narrative and cultural representations of the clinical encounter. Indeed, growing empirical evidence suggests that the skilful use of emotion by providers can be a powerful tool to promote patient safety and influence patient decision-making (Ferrer and Mendes 2018; Heyhoe et al. 2016). Even epidemiologic data have an affective component. Quantifying mass death is a deeply emotional and culturally resonant task, the impacts of which social scientists have documented with respect to COVID-19 (Aslam et al. 2020). 
Together medicine and epidemiology have expansive affective reach, from individual patients to policies that, if wrong, can cause significant harm. And since the advent of COVID-19, these disciplines have been granted sweeping cultural and political authority (Limaye et al. 2020). By grounding the feelings of healthcare providers and researchers in the historical context of the presente.g., grief for the life lost, rage at the impotent political response, or the emotional responsibility needed to deliver care during a crisis-affect theory can supplement epidemiologic models and clinical practice to help clinicians and researchers leverage their newfound power to build an ethical and effective response to COVID-19.

One of many influential voices in the development of affect theory, the literary critic Lauren Berlant's work is particularly incisive for healthcare professionals working on COVID-19. Across a three-decade career, she has argued that American national identity has been determined largely through the use of emotion by political and cultural leaders, rather than texts like the Constitution or individual moral determination (Berlant 1999). For example, she asserts that the success of the Reagan revolution in American politics was not only the administration's right-aligned policy victories but its use of emotion to advance private life and individual experience as replacements for the communitarianism and collective consciousness that characterized the New Deal and Civil Rights eras. This shift is evidenced in part by that administration's delayed response to the AIDS epidemic, which couched the disease as a "lifestyle" illness of personal behaviour and individual choice rather than an epidemic to be treated at the population level (Fox 2005).

Berlant's cultural history of U.S. individualism grounds her theory of cruel optimism or the emotion felt through attachments to relationships that "exist when something you desire is actually an obstacle to your flourishing" (Berlant 2011, 1), an affective concept onto which we can reflect the social and political dimensions of the COVID-19 pandemic. She offers smoking cigarettes as an easy, literal example of a harmful activity to which people are emotionally attached, but her interpretation is broader. With respect to medicine, we might locate cruel optimism in a terminally ill patient's continued treatments, particularly if those treatments diminish quality of life.
In Berlant's view, cruel optimism primarily is associated with aspirations to "the good life" or the economic stability and comfort that come as reward for a life well lived and is synonymous with the American Dream. Economist Raj Chetty and colleagues, however, have identified large reductions in income mobility during the last half-century that suggest the good life has become more difficult to attain (Chetty et al. 2017). While a constellation of increased education, healthcare, and housing costs, degraded social and public health services, and flat wages have contributed to the fading of the good life in the United States (Boushey 2019), affect theory allows us to focus not on economic specifics but on the enduring hope that the good life remains possible despite empirical evidence to the contrary.

In the context of COVID-19, we can view the reopening of the American economy as cruel optimism in motion, making explicit the costs of this good life fantasy. The emotional attachment to reopening that politicians, pundits, and protesters have expressed is a hopeful assumption that once the shutdown ends, the good life will be restored, without pausing to reflect on the pre-existing inequities in health and economic outcomes that have placed an unfair burden from COVID-19 on those already experiencing the greatest health and social harms (van Dorn, Cooney, and Sabin 2020). From the perspective of healthcare professionals, the promise that the good life is just around the corner seems wilfully naïve at best, maliciously misleading at worst.

But since the start of the pandemic, we have seen healthcare workers leverage their affective power as advocates. A widely published photograph of a nurse in Denver, Colorado blocking the path of re-opening protesters was a galvanizing call for political engagement among health professionals (Noor 2020). Likewise, the movement of healthcare workers to publish self-portraits of faces bruised by masks was a direct appeal to policymakers to implement disease control measures (Law 2020). This affective politics is grounded not in cruel optimism but is a politics of hope fundamentally different from that of the good life fantasy. Hope here is not naïve but rather is a motivating companion to the anger and grief on the surface of their political actions. The question for healthcare workers now is how collective affective action can be used to channel the reopening proponents' good life fantasies 
away from individual security and toward a meaningful collective recovery that prioritizes the communities most harmed by COVID-19.

Comments made by the Lieutenant Governor of Texas Dan Patrick offer an instructive affective case study. During an interview with FOX News on March 23, 2020, the Lieutenant Governor said:

As a senior citizen, are you willing to take a chance on your survival in exchange for keeping the America that all America loves for your children and grandchildren? If that is the exchange, I'm all in ... That doesn't make me noble or brave or anything like that. I just think there are lots of grandparents out there in this country like me. (Levin 2020)

His plea to offer his own life in exchange for the economic prosperity of his children and grandchildren is presented as an appeal to common sense, with untold numbers of individuals just like him willing to do the same. Notably absent from Patrick's remarks are the emotions associated with loss: mourning, grief, or anger. He leverages patriotism and individual prosperity as emotional states to camouflage policies that he knows will do harm. And as a member of a privileged class, his overture is disingenuous. His life is at low risk compared to those of the individuals on the front lines of an economic reopening, aptly termed "essential workers."

Affect theory here makes plain the value system that props up Patrick's good life fantasy, a system that elides equity and justice for the collective in favour of individual comfort for a privileged few. Bringing this moral logic in contact with a social determinants of health framework, we can find the essential workers whose lives are at risk in the profound racial and economic inequities in health outcomes and social mobility that existed long before COVID-19 and that the pandemic has exacerbated (Devakumar et al. 2020). It is not surprising that social and environmental factors like air pollution, household overcrowding, and limited healthcare access are associated with elevated rates of COVID19 mortality among Black and Brown individuals (Millet et al., 2020). To ignore these inequities when planning the reopening would be a deliberate and active choice, not negligence or oversight.
It is important for healthcare workers today to remember the historical legacy of affect as a driver of healthcare policy. During the AIDS epidemic, the activist organization ACT-UP successfully harnessed emotion to bring the epidemic into the national conversation and pressure the federal government to fund treatment and research. With an absent federal response, emotions were necessary to establish a moral imperative to take AIDS seriously. Indeed, the majority of obituaries written for the activist and author Larry Kramer refer to his use of anger or rage as effective organizing tools (Specter 2020). Grief for the persons lost and outrage at the lack of popular concern-emotions largely absent from COVID-19 discourse-were foundational to the formation of ACT-UP and its direct actions and political mobilization (Gould 2009).

The legacy of the AIDS epidemic, particularly the skilful use of affect to enact meaningful policy change, offers a roadmap for our current pandemic response. The healthcare field can assemble as a newly empowered political force, a progressive counter to Berlant's observations about the Reagan administration's regressive use of emotion. ACT-UP harnessed emotion to make change without the public trust and political authority that the healthcare field now holds. Medical and public health professionals are starting from a place of power; as such, we have a responsibility to take a longer historical and wider structural view when planning and implementing the COVID-19 recovery.

Rather than allowing cruel optimism to wash over us or sitting idle while opportunists deploy emotion toward harmful ends, Berlant suggests that we instead must channel our affective attachments as tools to build "a world that is worth our attachment to it" (Berlant 2011, 263). But to realize such a world requires hope, as the political actions of healthcare workers demonstrate with clarity. The pandemic is not only the gravest public health crisis of our lifetimes but also an unprecedented opportunity to transform the healthcare system into a vehicle for equity and justice. As healthcare workers, it is crucial that our affects-particularly as they have been used to privilege one life over another, white life over Black life, rich life over poor lifenot undermine but prioritize the rebuilding of the Black, Brown, and working-class communities that 
have been hit hardest by COVID-19. The stakes are too high to return to normal. To live in a better society, we first must imagine it, or as Berlant might say, to feel it.

Acknowledgements This work was supported in part by the Rudin Medical Ethics and Humanities Fellowship at the New York University Grossman School of Medicine. Additional thanks to Jason L. Schwartz of the Yale School of Public Health for his thoughtful critique of an earlier draft of this manuscript.

\section{References}

Aslam, F., T.M. Awan, J.H. Syed, A. Kashif, and M. Parveen. 2020. Sentiments and emotions evoked by news headlines of coronavirus disease (COVID-19) outbreak. Humanities and Social Sciences Communications 7: 23.

Berlant, L. 1999. The queen of America goes to Washington city: Essays on sex and citizenship. Durham: Duke University Press.

- 2011. Cruel optimism. Durham: Duke University Press.

Berlant, L., and J. Greenwald. 2012. Affect in the end times. Qui Parle 20(2): 71-89.

Boushey, H. 2019. Unbound: How inequality constricts our economy and what we can do about it. Cambridge: Harvard University Press.

Chetty, R., D. Grusky, M. Hell, N. Hendren, R. Manduca, and J. Narang. 2017. The fading American Dream: Trends in absolute income mobility since 1940. Science 356(6336): 398-406.

Devakumar, F., G. Shannon, S.S. Bhopal, and I. Abubakar. 2020. Racism and discrimination in COVID-19 responses. Lancet 395(10231): 1194.

Ferrer R.A., and W.B. Mendes. 2018. Emotion, health decision making, and health behaviour. Psychology and Health. 33(1): 1-16.

Fox, D.M. 2005. AIDS and the American health polity: The history and prospects of a crisis of authority. Milbank Quarterly 83(4): 7-33.

Gould, D.B. 2009. Moving politics: Emotion and ACT-UP's fight against AIDS. Chicago: University of Chicago Press.
Heyhoe J., Y. Birks, R. Harrison, J. K. O'Hara, A. Cracknell, and R. Lawton. 2016. The role of emotion in patient safety: Are we brave enough to scratch beneath the surface? Journal of the Royal Society of Medicine 109(2): 52-58.

Law, T. 2020. Health care workers around the world are sharing bruised, exhausted selfies after hard days treating COVID19. Time, March 22. https://time.com/5807918/healthcare-workers-selfies-coronavirus-covid-19. Accessed July $13,2020$.

Levin, B. 2020. Texas Lt. Governor: Old people should volunteer to die to save the economy. Vanity Fair, March 24. https://www.vanityfair.com/news/2020/03/dan-patrickcoronavirus-grandparents. Accessed May 29, 2020.

Limaye, R.J., M. Sauer, J. Ali, et al. 2020. Building trust while influencing online COVID-19 content in the social media world. Lancet Digit Health 2(6): e277-e278.

Millett, G.A., A.T. Jones, D. Benkeser, et al. 2020. Assessing differential impacts of COVID-19 on black communities. Annals of Epidemiology 47(7): 37-44.

Noor, P. 2020. What happened when healthcare workers confronted anti-lockdown protesters-in one photo. The Guardian, April 20. https://www.theguardian.com/artan ddesign/2020/apr/20/photograph-healthcare-workersconfronted-anti-lockdown-protesters-denver. Accessed July 12, 2020.

Reddy, W.M. 2001. The navigation of feeling: A framework for the history of emotions. Cambridge: Cambridge University Press.

Sedgwick, E. 2003. Touching, feeling: Affect, pedagogy, performativity. Durham: Duke University Press.

Specter, M. 2020. The benevolent rage of Larry Kramer. New Yorker, May 28. https://www.newyorker.com/culture/posts cript/the-benevolent-rage-of-larry-kramer. Accessed May 29, 2020.

van Dorn, A., R.E. Cooney, and M.L. Sabin. 2020. COVID-19 exacerbating inequalities in the US. Lancet 395(10323): 1243-1244.

Publisher's note Springer Nature remains neutral with regard to jurisdictional claims in published maps and institutional affiliations. 